\title{
Mechanical Pressure, Not Genes, Makes Ovulate Parts Leaf-Like in Cycas
}

\author{
Xin Wang ${ }^{1}$, Bin Luo ${ }^{2}$ \\ ${ }^{1}$ State Key Laboratory of Palaeobiology and Stratigraphy, Nanjing Institute of Geology and Palaeontology, Nanjing, China; \\ ${ }^{2}$ Fairylake Botanical Garden, Shenzhen \& Chinese Academy of Sciences, Shenzhen, China. \\ Email: brandonhuijunwang@gmail.com,xinwang@nigpas.ac.cn
}

Received October $23^{\text {rd }}, 2013$; revised November $25^{\text {th }}, 2013$; accepted December $12^{\text {th }}, 2013$

Copyright (c) 2013 Xin Wang, Bin Luo. This is an open access article distributed under the Creative Commons Attribution License, which permits unrestricted use, distribution, and reproduction in any medium, provided the original work is properly cited.

\begin{abstract}
The so-called "megasporophylls" of Ginkgoales, Coniferales, and Gnetales have been proven metamorphosed shoots, making "megasporophyll" of Cycas the last one resembling a leaf. Why and how it is so in Cycas (the most ancient seed plant dated back to the Palaeozoic) become key questions because their answers are hinged with the fates of several hypotheses in botany. Here, we performed a controlled developmental experiment on the ovulate parts (megasporophylls) in a single strobilus of Cycas sexseminifera. By removing the neighboring ones, two of the ovulate parts were left isolated spatially from others, in contrast to others left intact. A half-year-long continuous observation indicates that the isolated ovulate parts change their ovule arrangement from initial pinnate into helical pattern, while the intact ones in the same strobilus remain pinnate as usual. Since all ovulate parts are in the same strobilus and controlled by the same genome in this case and the only difference is lack of pressure from neighbors for the isolated ones, the changes in ovule orientation and ovulate part morphology can only be attributed to the lack of mechanical pressure among the ovulate parts. Therefore, we conclude that mechanical pressure, not genes, controls the morphology of ovulate parts and contributes to the leaf-like ovulate part morphology in Cycas. This conclusion cautions previous superficial interpretations of plant morphology.
\end{abstract}

Keywords: Cycas; Megasporophyll; Megasporocladode; Mechanical Pressure; Gene; Seed Plant

\section{Introduction}

"Alles ist Blatt", so said Goethe, the father of plant morphology, more than two hundred years ago [1,2]. This statement has been influencing botanists over centuries [2-4]. It is not surprising that female fertile organs in gymnosperms are termed as "megasporophylls", meaning leaf-like organs bearing ovules, and carpels in angiosperms are accordingly interpreted as equivalents of megasporophylls. However, fertile organs of most extant gymnosperms, except Cycas, do not even appear like leaves [5-14]. Therefore, the validity of the term "megasporophyll" is hinged with whether ovulate parts (OP) of Cycas are true leaves in nature. Why do only Cycas's ovulate parts look like leaves? Due to genes, mechanical pressure, or something else? To answer these questions, here we performed a developmental morphological experiment on ovulate parts borne in the same, single individual strobilus of Cycas sexseminifera. The difference in morphology of ovulate parts in this experiment indi- cates that the so-called normal pinnate ovule arrangement in Cycas is due to mechanical pressure. This outcome, agreeing with previous works [15-17], sheds a new light on the shoot nature of ovulate organs of seed plants and undermines several existing theories.

\section{Materials and Methods}

We selected a plant of Cycas sexseminifera (FLBG/12/ csex/063) cultivated in the National Cycad Germplasm Resources Conservation Center, Shenzhen Fairylake Botanical Garden, China as the experiment object, mainly because the ovulate parts in this plant normally are tightly packaged and they demonstrate typical leaf-like appearance. To eliminate the potential influence of developmental and genetic variations on our outcome, we performed operation and observed the morphology of ovulate parts within a single strobilus. To test the effect of mechanical pressure on ovulate part morphology, we removed all but two ovulate parts in one quarter of the 
strobilus (operational sector) using a pair of scissors on May 30, 2012 while those in the remaining three quarters (control sector) of the strobilus were left intact. Then we continuously observed and recorded the development and morphology of all ovulate parts weekly until December 15, 2012. All ovulate parts were collected for observation. To examine the ovule arrangement on ovulate parts clearly, the trichomes on the surface were mechanically removed before photography. The general morphology of the ovulate parts was recorded with a Panasonic Lumix digital camera and a Samsung Vluu M110 camera, and the details were recorded with a Nikon SMZ1500 microscope with a digital camera. All images were organized together with Photoshop 7.0 for publication. The specimens were deposited in the Shenzhen Fairylake Botanical Garden, Guangdong, China.

\section{Results}

Before operation the strobilus of the plant appears just normal, with green ovulate parts helically arranged on the stem apex (Figure 2(a)). After scissoring some of the ovulate parts, two ovulate parts (OP 1 and OP 2, one above the other) are left isolated in the operational sector and have ample empty space around them, and the strobilus appears notched when viewed from the top (Figures 1(a), 2(c)). Unexceptionally, the removed ovulate parts of this stage are like the typical ones, namely, with their ovules of similar sizes arranged in two lateral ranks along the ovulate parts (Figures 1(b), 1(c), 2(b)). About two weeks later one ovule on each of the isolated ovulate parts becomes bigger than the others on the same ovulate part (Figures 1(f), 2(d)). Through the development the adjacent ovulate parts almost fill up the vacancy left by the removed ovulate parts and the strobilus recovers almost to its normal round configuration by December. The seeds of the plant mature and grow much bigger by December while the aborted ovules maintain their smaller size (Figures 1(d), 2(e)). All ovules or seeds from the control sector are uniformly arranged in two lateral ranks along the ovulate parts, just as expected, despite the variations in general ovulate part morphology and number of mature seeds (Figures 1(d), 2(e)). The two ovulate parts in the operational sector demonstrate unusual morphology (Figures 1(g)-(i)). The top one (OP 1) has lost two of its seeds and preserves others as aborted ovules (Figure 1(g)). The two fallen seeds have left two scars on the ovulate part (Figures 1(h), (i)). The arrangement of these two seed scars and one of the ovules suggests a helical pattern along the ovulate part (Figures 1(h), (i)).

\section{Discussion}

The etymology of the term "megasporophyll" implies that megasporophyll is essentially a leaf. Naturally, megasporophyll (ovulate part) is grouped with cataphyll and foliage leaf into a single category, "foliar organs" [18]. Ideally a leaf is a bilateral, dorsiventral organ, usually restricted to a single plane $[19,20]$. Anatomically the deployment of vascular bundle in a leaf is distinct from that in a branch. Therefore, whether the ovulate part is really a leaf can be tested at least using these two criteria.

Borne on the same individual strobilus, all of the ovulate parts studied here share the same genome. Under this condition the difference in ovulate part morphology cannot be attributed to genes. The only difference introduced in this experiment is whether there are space and mechanical pressure among ovulate parts. Since availability of space and lack of mechanical pressure are inseparable in this experiment, they will be taken as a single factor hereafter.

Our observation on OP 1 in the operational sector indicates that the ovules are not arranged on the laterals of the ovulate part as expected for a leaf. Obviously one of the seed scars has crossed the midline of the ovulate part (Figure 1(h)). There are two alternative interpretations for this phenomenon. The first one is that the original position of the seed scar is more or less on the adaxial surface of the ovulate part stalk. This would imply that the original ovule arrangement is initially not lateral but helical, refuting the leaf nature of ovulate part. The second one is that original position of the seed was lateral on the ovulate part stalk (just like the "normal" ovulate parts seen in Figures 1(b), 1(c), 2(b)), and the displaced position of the seed scar is due to external pressure or other factors in the late development. However, this "abnormal" ovulate part shares the same intrinsic genetics and developmental environment with all other normal ones. The only difference between this "abnormal" and other normal ovulate parts is that the former lacks external mechanical pressure from its peers. Therefore the mechanical pressure among the ovulate parts is the only culprit responsible for the pinnate leaf-like morphology of ovulate parts (megasporophylls), and its absence is responsible for the "abnormal" morphology. Lack of this pressure allows ovulate parts to freely fulfill their original, normal morphological potential that is controlled by intrinsic genetics. Therefore abnormal-appearing ovulate parts in this experiment actually reflect more inherent essence of ovulate parts in Cycas. Thus the ovules/seeds in Cycas were originally helically borne along a branch, their pinnate arrangement in ovulate parts is a superficial pseudomorphy due to the coercion of mechanical pressure among ovulate parts.

This conclusion is in agreement with other independent observations and studies. Non-pinnate arrangement of ovules in about half of ovulate parts has been observed in Cycas rumphii, which has more elongated, laxly arranged ovulate parts [21]. Three dimensional branching of vas- 

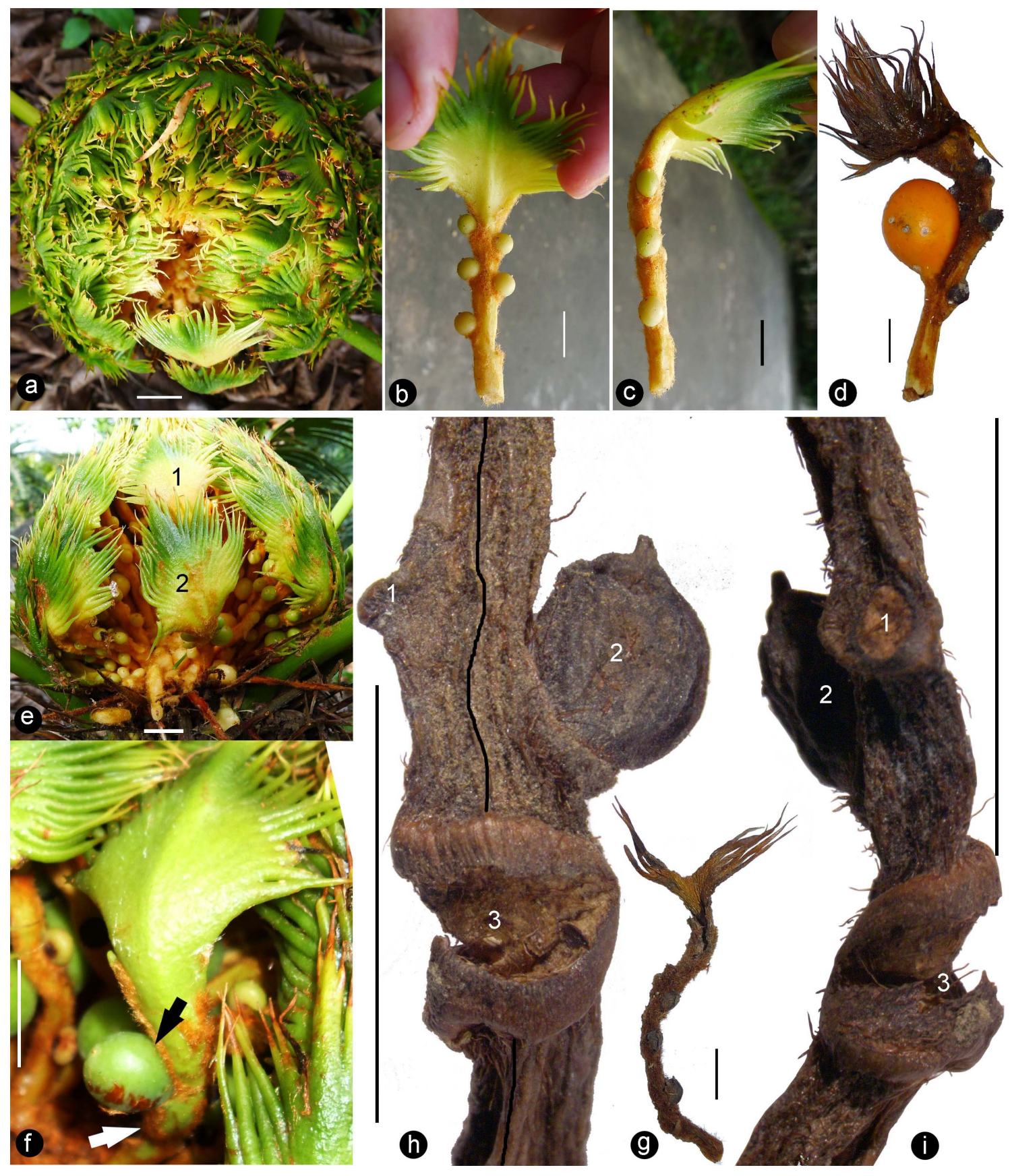

Figure 1. A strobilus of Cycas sexseminifera and its ovulate parts in various stages. All bars are $1 \mathrm{~cm}$ long. Specimen number for (b)-(d) is 2012.11.LN.009, for F-I is 2012.11.LN.009a. (a) Top view of the strobilus after removing many ovulate parts in the operational sector (bottom). Plant number FLBG/12/csex/063. (b) Adaxial surface view of an immature ovulate part in late May, showing the typical two rank arrangement of ovules. (c) Side view of the same ovulate part as in (b), showing the typical two rank arrangement of ovules, with all ovules in the same plane. (d) A mature ovulate part in middle December, showing the typical two rank arrangement of ovules and one mature seed along the crooked ovulate part. (e) Side view of the strobilus in (a) showing only two ovulate parts $(1,2)$ left in the operational sector. (f) Megasporophyll 1 in (e) on June 11. Note the orientation and size of the developed seed (black arrow) in contrast to the aborted ovule (white arrow). The developed seed leaves a scar in (h) and (i). (g) Megasporophyll 1 in (e) on December 15. Note the developed seed has fallen off and only the aborted ovules are still attached to the ovulate part stalk. H. Adaxial surface view of the proximal of the ovulate part in (g), after removing the trichomes. The black line marks the midline of the ovulate part. Note the positions of a scar left by a missing ovule (1), an aborted ovule (2), and a seed scar (3) across the midline. The seed scar is left by the developed seed shown in (f). (i) Side view of the proximal of the ovulate part in (g). Note the positions of a scar left by a missing ovule (1), an aborted ovule (2), and a seed scar (3) that is left by a fallen seed. 

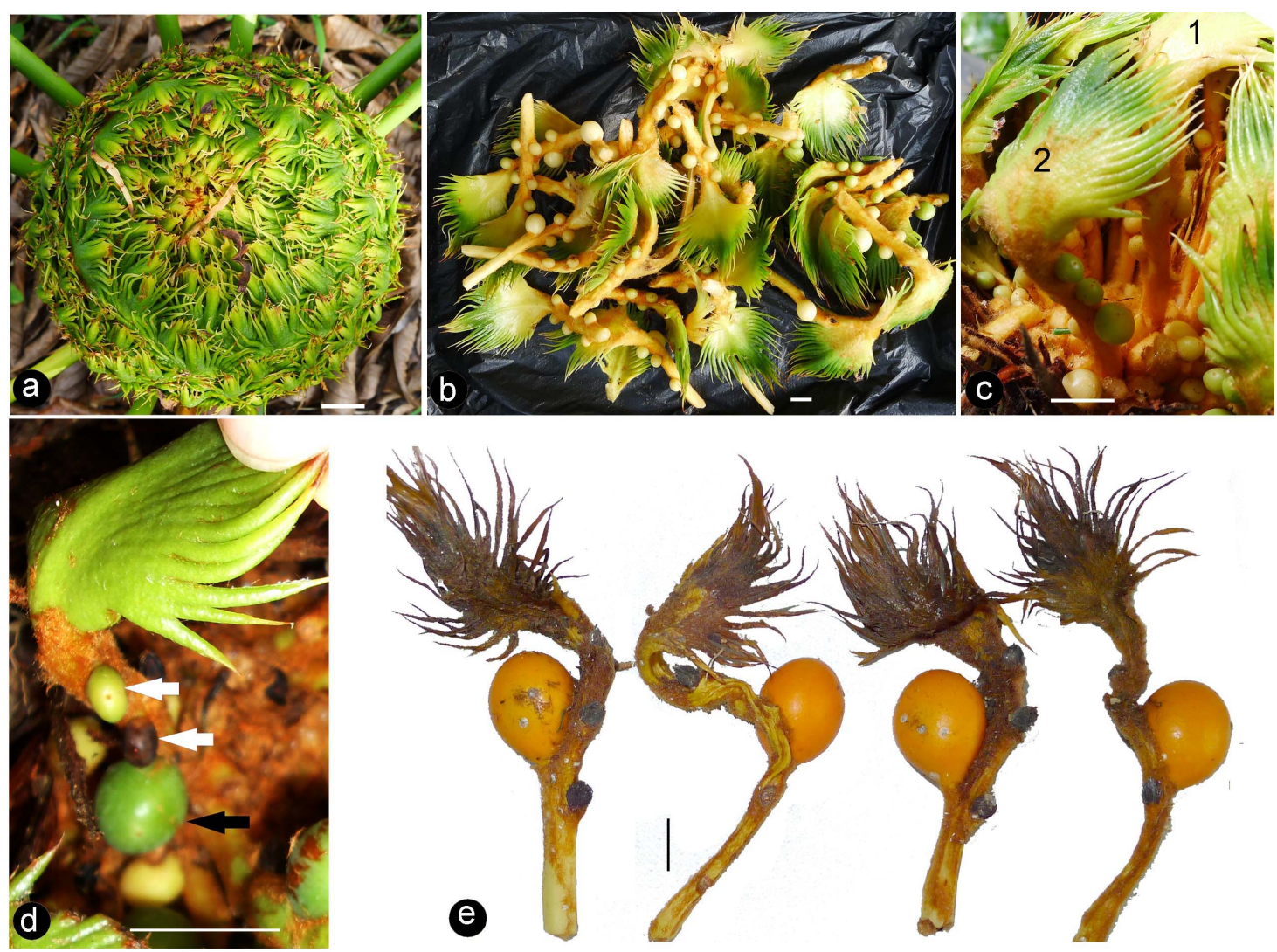

Figure 2. The strobilus of Cycas sexseminifera and its ovulate parts in various stages. All bars are $1 \mathrm{~cm}$ long. (a) Top view of the strobilus before removing any ovulate parts. Plant number FLBG/12/csex/063. (b) Removed ovulate parts with typical pinnate configuration. Specimen number 2012.11.LN.009. (c) Oblique view of the operated strobilus in late May, showing only two megasporophylls $(1,2)$ left in the operational sector with lateral ovules. (d) Megasporophyll 2 in Figure 1(e) on June 11. Note the orientation and size of the developed seed (black arrow) in contrast to the aborted ovules (white arrows). Specimen number 2012.11.LN.009b. (e) Adaxial surface view of several normal ovulate parts on December 15, showing the typical two rank arrangement of ovules and seeds despite variations in morphology. Specimen number 2012.11.LN.009.

cular bundles has been observed in cycad ovulate parts, and girdling traces that are typical and characteristic for foliage leaves of Cycads are completely lacking in cycad ovulate parts [15]. Unlike collateral bundles expected for foliage leaves [22-25], amphicribral bundles are regularly seen in ovulate parts of Cycads (Cycas, Bowenia, Dioon, Zamia, and Stangeria) and some of the them even have secondary growth [26]. Parallel to the above, the occurrence of three ovules (two on one side) at the same level on an ovulate part of Zamia leiboldii (Figure 25 of [26]) is hard to reconcile with the assumed foliar morphology of the ovulate part. Together with our observation here, all these converge to a conclusion: the ovulate parts in Cycads are not leaves, their leaf-like appearance is a masquerade due to mechanical pressure rather than a reflection of the inherent nature of plant. Actually similar conclusions have been reached by Melville and Meeuse $[16,17]$ long ago, but, unfortunately, their suggestions were largely ignored because of reasons. Now under the new light from our experiment, it becomes more obvious that "megasporophyll" is a misnomer, which should be replaced by "megasporocladode" (a branch bearing ovules), as suggested by Meeuse in1963.

\section{Conclusion}

The pinnate morphology of the ovulate parts in Cycas is a superficial pseudomorphy due to the mechanical pressure. It has little to do with the inherent essence of the organ. Therefore, the formerly assumed foliar nature of the megasporophyll of Cycas is purely a take-for-grant assumption that has no ground in botany. The non-existence of "megasporophyll" will leave many botanical theories groundless.

\section{Acknowledgements}

The authors claim no conflict of interest. We thank Dr. Nan Li for her help during this study. This research is supported by the National Basic Research Program of China (973 Program 2012CB821901), and Team Program of Scientific Innovation and Interdisciplinary Cooperation, CAS (2013-2015). 


\section{REFERENCES}

[1] J. W. V. Goethe, "Versuch die Metamorphose der Pflanzen zu Erklären,” Carl Wilhelm Ettinger, Gotha, 1790.

[2] D. R. Kaplan, "The Science of Plant Morphology: Definition, History, and Role in Modern Biology,” American Journal of Botany, Vol. 88, No. 10, 2001, pp. 1711-1741. http://dx.doi.org/10.2307/3558347

[3] R. Classen-Bockhoff, "Plant Morphology: The Historic Concepts of Wilhelm Troll, Walter Zimmermann and Agnes Arber," Annals of Botany, Vol. 88, No. 6, 2001, pp. 1153-1172. http://dx.doi.org/10.1006/anbo.2001.1544

[4] M. C. Dornelas and O. Dornelas, "From Leaf to Flower: Revisiting Goethe's Concepts on the 'Metamorphosis' of Plants,” Brazilian Journal of Plant Physiology, Vol. 17, No. 4, 2005, pp. 335-344. http://dx.doi.org/10.1590/S1677-04202005000400001

[5] Z. Zhou, S. Zheng and L. Zhang, "Morphology and Age of Yimaia (Ginkgoales) from Daohugou Village, Ningcheng, Inner Mongolia, China,” Cretaceous Research, Vol. 28, No. 2, 2007, pp. 348-362.

http://dx.doi.org/10.1016/j.cretres.2006.05.004

[6] E. D. Brenner, D. W. Stevenson and R. W. Twigg, “Cycads: Evolutionary Innovations and the Role of PlantDerived Neurotoxins," Trends in Plant Science, Vol. 8, No. 2003, pp. 446-452.

[7] P. Martens, “Les Gnetophytes,” Gebrueder Borntraeger, Berlin, 1971.

[8] R. Florin, “The Morphology of Trichopitys heteromorpha Saporta, a Seed Plant of Palaeozoic Age, and the Evolution of the Female Flowers in the Ginkgoinae," Acta Horti Bergiani, Vol. 15, No. 5, 1949, pp. 79-109.

[9] S. Zheng and Z. Zhou, “A New Mesozoic Ginkgo from Western Liaoning, China and Its Evolutionary Significance," Review of Palaeobotany and Palynology, Vol. 131, No. 1-2, 2004, pp. 91-103. http://dx.doi.org/10.1016/j.revpalbo.2004.03.002

[10] Z. Zhou and S. Zheng, "The Missing Link in Ginkgo Evolution,” Nature, Vol. 423, No. 6942, 2003, pp. 821822. http://dx.doi.org/10.1038/423821a

[11] F. J. F. Shaw, "A Contribution to the Anatomy of Ginkgo biloba,” New Phytologist, Vol. 7, No. 4-5, 1908, pp. 8593. http://dx.doi.org/10.1111/j.1469-8137.1908.tb06074.x

[12] G. W. Rothwell and R. A. Stockey, "Evolution and Phylogeny of Gnetophytes: Evidence from the Anatomically Preserved Seed Cone Protoephedrites eamesii gen. et sp. nov. and the Seeds of Several Bennettitalean Species,” International Journal of Plant Sciences, Vol. 174, No. 3, 2013, pp. 511-529.

[13] A. J. Eames, “The Relationships of Ephedrales,” Phyto- morphology, Vol. 2, No. 1, 1952, pp. 79-100.

[14] A. Carlsbecker, J. F. Sundström, M. Englund, D. Uddenberg, L. Izquierdo, A. Kvarnheden, F. Vergara-Silva and P. Engström, "Molecular Control of Normal and Acrocona Mutant Seed Cone Development in Norway Spruce (Picea abies) and the Evolution of Conifer Ovule-Bearing Organs," New Phytologist, Vol. 200, No. 1, 2013, pp. 261-275. http://dx.doi.org/10.1111/nph.12360

[15] D. W. Stevenson, "Morphology and Systematics of the Cycadales," Memoirs of the New York Botanical Garden, Vol. 57, No. 1, 1990, pp. 8-55.

[16] R. Melville, “A New Theory of the Angiosperm Flower: I. The Gynoecium,” Kew Bulletin, Vol. 16, No. 1, 1962, pp. 1-50. http://dx.doi.org/10.2307/4120346

[17] A. D. J. Meeuse, "From Ovule to Ovary: A Contribution to the Phylogeny of the Megasporangium," Acta Biotheoretica, Vol. XVI, No. 3-4, 1963, pp. 127-182. http://dx.doi.org/10.1007/BF01556603

[18] E. J. Hermsen, T. N. Taylor, E. L. Taylor and D. W. Stevenson, "Cataphylls of the Middle Triassic Cycad Antarcticycas schopfii and New Insights into Cycad Evolution," Americna Journal of Botany, Vol. 93, No. 5, 2006, pp. 724-738. http://dx.doi.org/10.3732/ajb.93.5.724

[19] A. M. F. Tomescu, "Megaphylls, Microphylls and the Evolution of Leaf Development," Trends in Plant Science, Vol. 14, No. 1, 2008, pp. 5-12. http://dx.doi.org/10.1016/j.tplants.2008.10.008

[20] S. Hao and J. Xue, "Earliest Record of Megaphylls and Leafy Structures, and Their Initial Diversification," Chinese Science Bulletin, Vol. 58, No. 23, 2013, pp. 2784 2793. http://dx.doi.org/10.1007/s11434-013-5799-x

[21] X. Wang, D. Stevenson and N. Li, "Doubt on the Foliar Nature of Cycad Megasporophylls,” Botanical Society of America Annual Meeting, Columbus, 10 July 2012, ID: 841.

[22] Z.-T. Guan and L. Zhou, "Cycads of China," Sichuan Science and Technology Press, Chengdu, 1996.

[23] F. Wang, H. Liang, T. Chen and D. Wang, "Cycads in China,” Guangdong Science \& Technology Press, Guangzhou, 1996.

[24] D.-X. Xiao, “Anatomy of the Vegetative Organs of Cycas szechuanensis," Journal of Zhongkai University of Agriculture and Technology, Vol. 18, No. 3, 2005, pp. 1-5.

[25] Y.-J. Tang and J.-P. Liao, "Studies on Comparative Anatomy of the Pinnae of Six Species of Cycas," Chinese Bulletin of Botany, Vol. 18, No. 5, 2001, pp. 615-622.

[26] W. C. Worsdell, "The Vascular Structure of the Sporophylls of the Cycadaceae,” Annals of Botany, Vol. os-12, No. 2, 1898, pp. 203-241. 